\title{
Analysis of thermal effect on residual stresses of broached Inconel 718
}

\author{
Z. Chen ${ }^{1, a^{*}}$, R. Lin Peng, b, P. Avdovic ${ }^{2, c}$, J. Moverare ${ }^{1,2, d}$, F. Karlsson ${ }^{2, ~ e}$, \\ J.M. Zhou ${ }^{3, \mathrm{f}}$, S. Johansson ${ }^{1, g}$ \\ ${ }^{1}$ Division of Engineering Materials, Linköping University, SE-58183 Linköping, Sweden \\ ${ }^{2}$ Siemens Industrial Turbomachinery AB, SE-61283 Finspång, Sweden \\ ${ }^{3}$ Division of Production and Materials Engineering, Lund University, SE-22100 Lund, Sweden \\ a, * zhe.chen@liu.se, b ru.peng@liu.se, c pajazit.avdovic@siemens.com, ${ }^{d}$ johan.moverare@liu.se, \\ e fredrik.n.karlsson@siemens.com, ${ }^{f}$ Jinming.Zhou@iprod.Ith.se, ${ }^{9}$ sten.johansson@liu.se
}

Key words: Broaching, Inconel 718, Residual stresses, Thermal exposure, Recrystallization

\begin{abstract}
Inconel 718 is a nickel based superalloy that is widely used as a turbine disc material in gas turbine industries. This study details the effect of thermal exposure on the residual stresses produced when broaching Inconel 718. The chosen parameters for broaching in this study are similar to those used when manufacturing turbine discs. The broaching operation produced a high level of tensile residual stresses at the broached surface. A layer with tensile residual stresses was formed in the sub-surface region, followed by a layer several times thicker with compressive residual stresses. Thermal exposure was conducted at $550{ }^{\circ} \mathrm{C}$. The depth distributions of residual stresses after thermal exposure are presented and discussed in this paper. Complete relaxation of the surface tensile residual stresses was observed after $30 \mathrm{~h}$ thermal exposure, whereas the $3000 \mathrm{~h}$ thermal exposure influenced both the surface and sub-surface residual stress states.
\end{abstract}

\section{Introduction}

The main machining process of Inconel 718 in gas turbine industries is to broach fir-tree root fixings for gas turbine blade mounting. Previous studies have shown poor machinability of Inconel 718 alloys [1,2]. Residual stresses are produced as a consequence of inhomogeneous plastic deformation and severe heat generation during the machining process. The residual stress profile generated when turning Inconel 718 is generally tensile at the machined surface followed by a gradual decrease with an increasing depth [3-5]. But currently few papers mention the distribution of residual stresses in broached Inconel 718. Residual stresses affect the fatigue behavior of machined components by changing the mean stress and stress amplitude. Compressive stresses are generally beneficial when taking fatigue into account, whereas tensile residual stresses are usually considered to be detrimental since they can accelerate the formation and propagation of fatigue cracks [6]. Therefore, it is of great importance to study residual stress profiles in order to better understand the fatigue behavior in broached Inconel 718.

Residual stresses produced during manufacturing can be reduced or completely relaxed by the application of thermal energy. The elastic strains associated with residual stresses can be converted to micro-plastic strains, resulting in stress relaxation [7]. The relaxation behavior or the stability of machining residual stresses is of fundamental and practical interest especially for high temperature applications. Tensile residual stresses which may lead to subsequent component failure have to be reduced, whereas beneficial compressive residual stresses are desired to be stable from the point of view of the fatigue approaches. The following experimental work was performed in order to measure the residual stress profile produced when broaching Inconel 718. The broaching process used in this study is similar to that used for machining fir-tree root fixings for mounting gas turbine blades. The thermal effect on the broached residual stresses has been discussed in this study as well.

\section{Experimentals}

A test sample was taken from a heat treated Inconel 718 forging with the chemical composition given in Table 1. The forging was solution heat treated at $970{ }^{\circ} \mathrm{C}$ for $3.5 \mathrm{~h}$. The first ageing was performed at $720{ }^{\circ} \mathrm{C}$ for $8 \mathrm{~h}$, followed by the second ageing at $620{ }^{\circ} \mathrm{C}$ for $8 \mathrm{~h}$. At the edge of the test 
sample, notches with fir-tree profiles were broached, as shown in Fig. 1(a) with semi-worn PM-T15 tools (a tungsten type high speed steel with hardness of 65-67 HRC), oil coolant and with a fixed cutting speed of $\mathrm{v}_{\mathrm{c}}=3 \mathrm{~m} / \mathrm{min}$. Three specimens were cut to expose the broached surface for microstructural studies and residual stress measurements, as shown in Fig. 1(b). One was kept in the as-broached condition; the other two were thermally exposed at $550{ }^{\circ} \mathrm{C}$ for $30 \mathrm{~h}$ and $3000 \mathrm{~h}$ respectively followed by air cooling.

Table 1 Chemical composition (wt. \%) of Inconel 718

\begin{tabular}{ccccccccc}
\hline $\mathrm{Ni}$ & $\mathrm{Cr}$ & $\mathrm{Nb}$ & $\mathrm{Mo}$ & $\mathrm{Ti}$ & $\mathrm{Al}$ & $\mathrm{C}$ & $\mathrm{Si}$ & $\mathrm{Fe}$ \\
53.8 & 18.1 & 5.5 & 2.9 & 1 & 0.55 & 0.25 & 0.04 & Balance \\
\hline
\end{tabular}

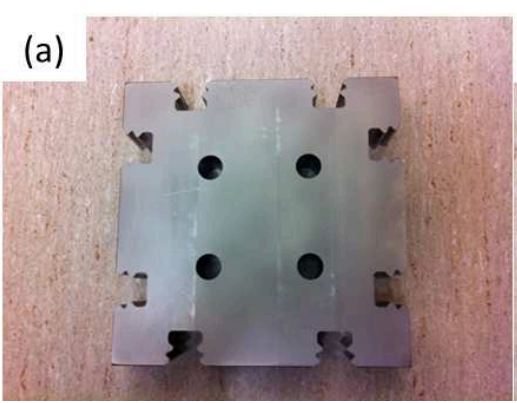

(b)

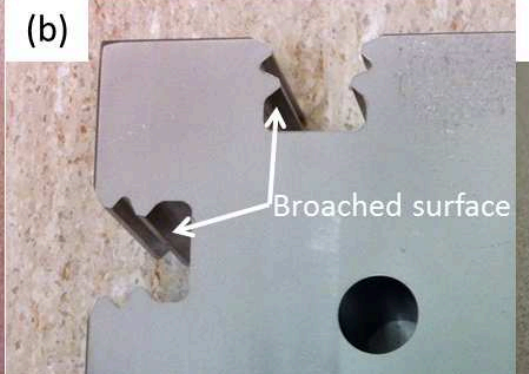

(c)

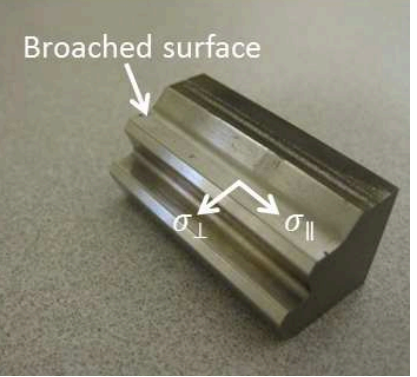

Fig. 1 (a) Broached notches with fir-tree profiles; (b) The broached surface for microstructural studies and residual stress measurements; (c) Two measured in-plane stress directions

Residual stress measurements were made on all three specimens using X-ray diffraction. Two inplane stress directions were measured on the broached surfaces, parallel and perpendicular to the broaching direction $\left(\sigma_{\|}\right.$and $\left.\sigma_{\perp}\right)$, as shown in Fig. 1(c). Cr- $\mathrm{K}_{\alpha}$ radiation was chosen, giving a diffraction peak at $2 \theta \sim 128^{\circ}$ for the $\{220\}$ family of lattice planes of the nickel-based matrix. Peaks were measured at nine $\psi$-angles between $\psi= \pm 45^{\circ}$. Residual stresses were calculated based on the " $\sin ^{2} \psi$ " method [8] with an X-ray elastic constant of $4.65 \times 10^{-6} \mathrm{MPa}^{-1}$ which is commonly used for $\{220\}$ diffraction planes of the nickel-based matrix of Inconel 718 . The depth profiles were obtained by electrolytical polishing with Struers LectroPol-5 on an area of $11 \mathrm{~mm}$ in $\sigma_{\|}$times $5 \mathrm{~mm}$ in $\sigma_{\perp}$ with a depth varying between $5 \mu \mathrm{m}$ and $50 \mu \mathrm{m}$. Microstructural studies were conducted in a Hitachi SU-70 scanning electron microscope (SEM). By using the electron channeling technique, diffraction contrast images can be obtained. Strain and the presence of defects can distort lattice planes. The distortion of lattice planes will give electron channeling contrast (ECC) [9], which offers an approach for better understanding of the plastic deformation under the broached surface.

\section{Experimental results}

An electron channeling image showing the microstructure with several characteristics of plastic deformation under the broached surface is illustrated in Fig. 2(a). A thin layer with an irresolvable microstructure was formed at the broached surface. When zooming in on the surface layer, refined grains can be identified as shown in Fig. 2(b). V. Bushlya et al. characterized the surface layer when turning Inconel 718 with a high cutting speed of $300 \mathrm{~m} / \mathrm{min}$, and nano-crystalline grains varying from $50 \mathrm{~nm}$ to $150 \mathrm{~nm}$, mainly attributed to grain subdivision and dynamic recrystallization were identified using a transmission electron microscope [10]. In the sub-surface region, grains orientate towards the broaching direction due to the high cutting forces. Slip bands with various orientations in the deformed grains reveal a high level of plastic deformation induced by the broaching process. After $30 \mathrm{~h}$ thermal exposure at $550{ }^{\circ} \mathrm{C}$, some recrystallized grains were dispersed in the surface layer especially at the broached surface as shown in Fig. 2(c), while more recrystallized grains with a larger size were observed in the surface layer as the thermal exposure time increased to $3000 \mathrm{~h}$ as shown in Fig. 2(d). 

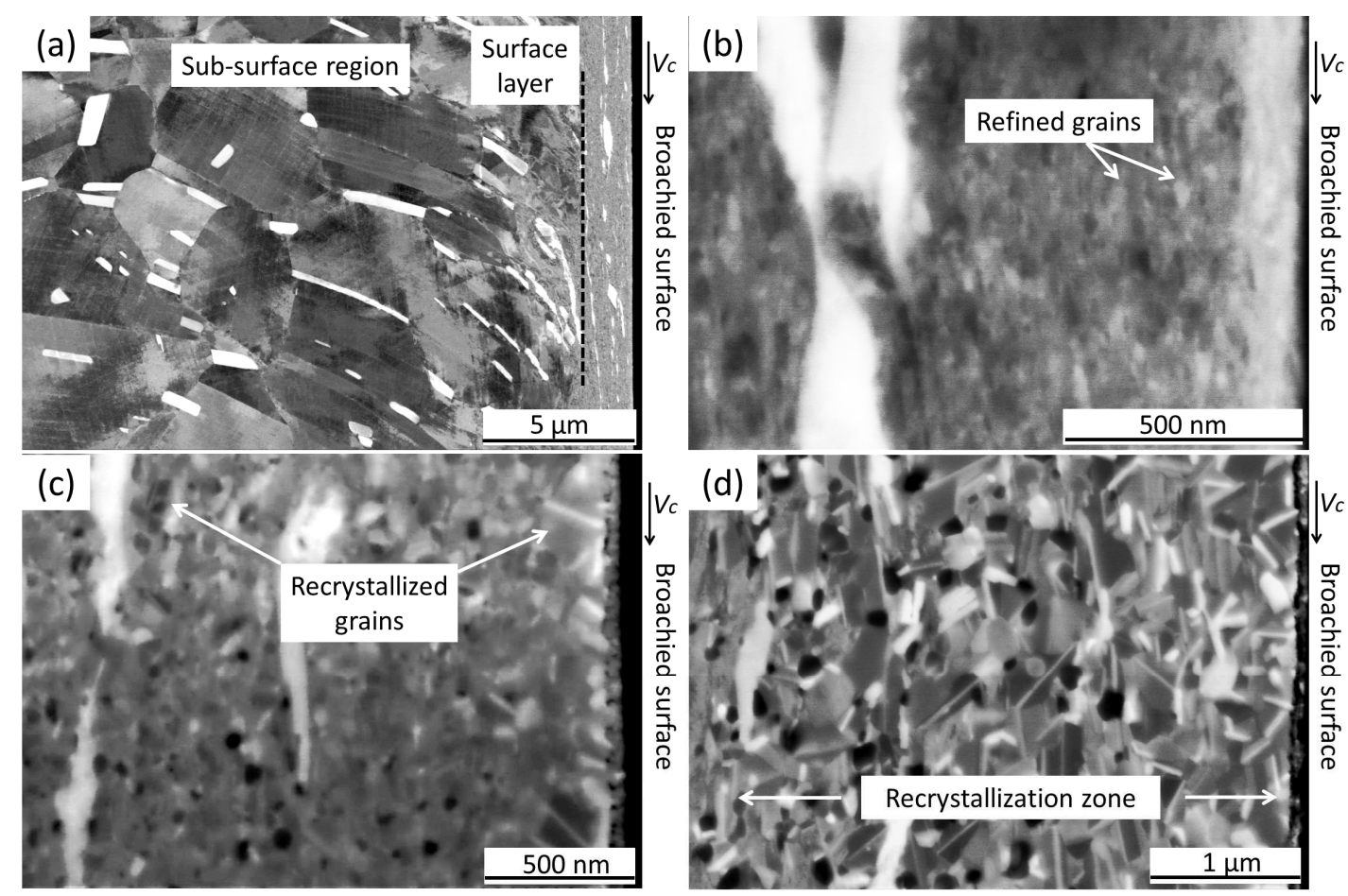

Fig. 2 ECC images showing (a) severe plastic deformation under the broached surface; (b) refined structure in the surface layer; (c) recrystallized grains in the surface layer after $30 \mathrm{~h}$ thermal exposure; (d) Recrystallization zone formed in the surface layer after $3000 \mathrm{~h}$ thermal exposure

The residual stress depth profiles differ between the two directions $\left(\sigma_{\|}\right.$and $\left.\sigma_{\perp}\right)$ and the three specimens as shown in Fig. 3. For the as-broached specimen, the broaching operation produced high tensile residual stresses at the surface. In the sub-surface region, a thin layer exhibiting tensile residual stresses was formed under the broached surface, followed by a layer with compressive residual stresses that is several times thicker than the tensile layer. The maximum tensile stress in $\sigma_{\|}$appears at a depth of $\sim 10 \mu \mathrm{m}$ under the broached surface with a higher value of $727 \pm 61 \mathrm{MPa}$ in comparison with that of $270 \pm 130 \mathrm{MPa}$ in $\sigma_{\perp}$ at the broached surface. After $30 \mathrm{~h}$ thermal exposure, in both $\sigma_{\|}$and $\sigma_{\perp}$ the surface residual stresses were relaxed to a value close to zero. The maximum tensile stress in $\sigma_{\|}$dropped to $572 \pm 42 \mathrm{MPa}$, whereas it still remains at a similar level in $\sigma_{\perp}$ in comparison with that of the as-broached specimen. No relaxation in the compressive residual stresses was observed in the sub-surface region. After $3000 \mathrm{~h}$ thermal exposure, the surface residual stresses are reversed to compression with a value of $\sim-200 \mathrm{MPa}$ in both $\sigma_{\|}$and $\sigma_{\perp}$. The tensile residual stresses in the sub-surface region were considerably reduced in $\sigma_{\|}$, and were entirely removed in $\sigma_{\perp}$. In addition, the profile after $3000 \mathrm{~h}$ thermal exposure showed larger compressive residual stresses in the sub-surface region in both $\sigma_{\|}$and $\sigma_{\perp}$.

The full width at half maximum (FWHM) of X-ray diffraction peaks is related to the density of defects in the material [11]. A decrease of FWHM with an increasing depth under the broached surface as shown in Fig. 4 reveals a gradient of plastic deformation from the surface to the bulk material as observed previously in microstructure. The $30 \mathrm{~h}$ thermal exposure slightly reduced peak broadening at the surface revealing that the recrystallization as shown in Fig. 2(c) is in the early stage, thereby only partially eliminating the dislocations in the surface layer. After $3000 \mathrm{~h}$ thermal exposure, the fully recrystallization, as shown previously in Fig. 2(d) annihilated most of the dislocations in the surface layer resulting in a dramatic drop of FWHM at the broached surface. The FWHM value in the sub-surface region has not noticeably changed after the thermal exposure. 
(a)

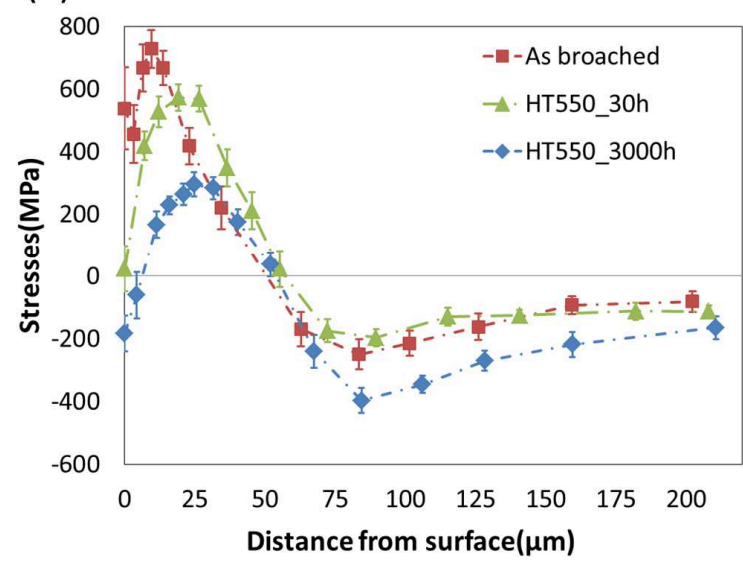

(b)

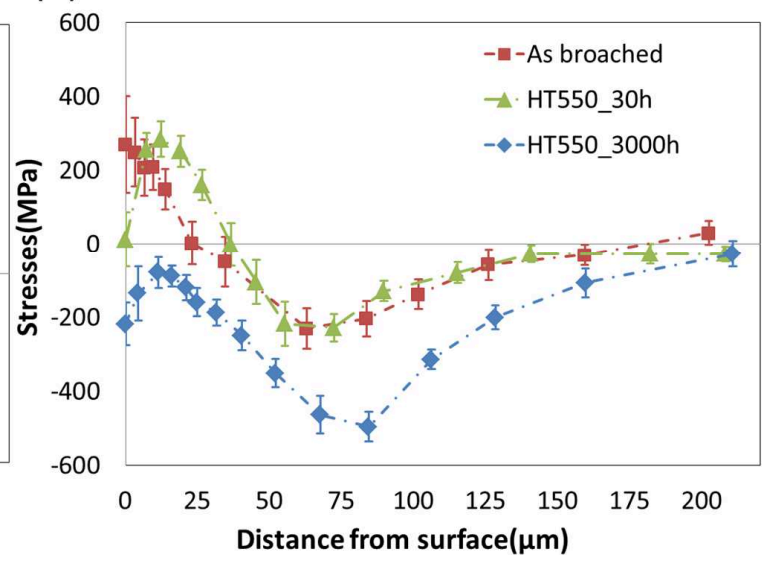

Fig. 3 The residual stress depth profiles in (a) the $\sigma_{\|}$direction; (b) the $\sigma_{\perp}$ direction

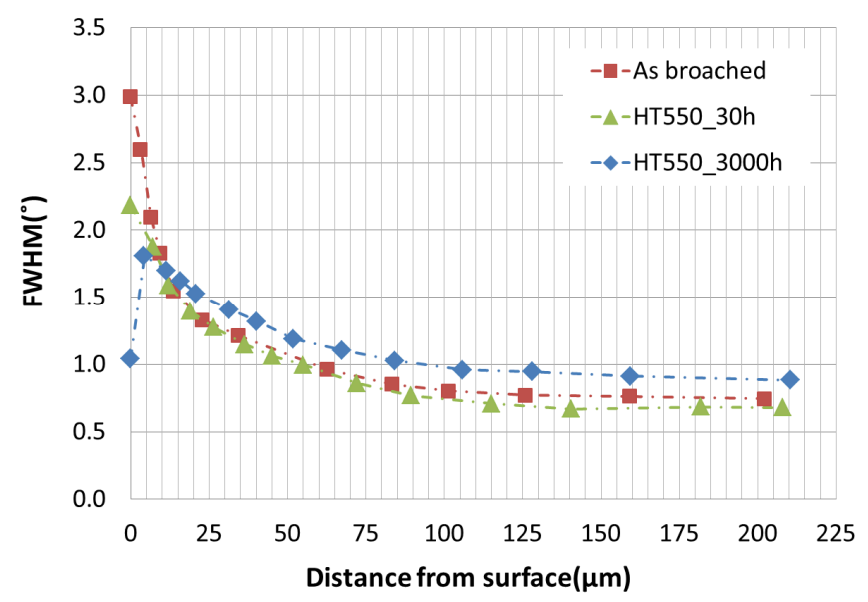

Fig. 4 Comparison of full width at half maximum

\section{Discussion}

Residual stresses in machining are produced as a consequence of non-uniform plastic deformation induced by mechanical and thermal loadings. Plastic deformation due to cutting forces contributes to giving compressive residual stresses, whereas deformation as a consequence of thermal expansion produces tensile residual stresses during the subsequent cooling [2]. In a machined component, mechanically and thermally induced residual stresses always exist simultaneously. The thermal effect is normally dominant in high-speed turning of Inconel 718 where high temperatures are presented, thereby causing undesired tensile residual stresses at the surface and in the subsurface region [2]. In the case of broaching, the cutting material that is commonly used in industry is high speed steel, which limits cutting speeds in a range of $v_{c}=2-8 \mathrm{~m} / \mathrm{min}$ when cutting Ni-based alloys which is much lower than that in turning. In this study, the broaching speed was $3 \mathrm{~m} / \mathrm{min}$. The high level of tensile residual stresses produced at the broached surface as shown in Fig. 3 indicates that the thermal effect still plays a predominant role when broaching Inconel 718 at very low cutting speeds. Dynamic recovery and recrystallization normally occur when severely deforming Inconel 718 at high temperatures [12]. The refined grains as shown in Fig. 2(b) have revealed dynamic recrystallization might occur in the surface layer during the broaching process, and the dynamic recrystallization could be a factor that is responsible for the stress relaxation in $\sigma_{\|}$ at the surface of the as-broached specimen.

When subjected to thermal energies at high temperatures, the residual stress relaxation could arise from either an oriented slip of dislocations or recrystallization. The former process transforms elastic residual strains into micro-plastic strain, while recrystallization can eliminate most dislocations in the deformed region [7]. Since the microstructural study as shown in Fig. 2(c) has 
indicated that recrystallization occurred in the early stage in the severely deformed surface layer after $30 \mathrm{~h}$ thermal exposure at $550{ }^{\circ} \mathrm{C}$, complete relaxation of residual stresses can be expected at the broached surface, as shown in Fig. 3. Thermal residual stress-relaxation is not only affected by the applied annealing temperature and time, the residual stress state itself, but also by the material properties [7]. Inconel 718 is an alloy strengthened by solute atoms and coherent precipitates. When subjected to thermal exposure, the presence of solute atoms and precipitates reduce the mobility of dislocations, thereby hindering the recovery process. Thus after $30 \mathrm{~h}$ thermal exposure, only slight stress relaxation was observed in $\sigma_{\|}$in the sub-surface region as shown in Fig. 3.

As the thermal exposure time increased to $3000 \mathrm{~h}$, the long-term thermal exposure produced a fully recrystallized zone in the surface layer as shown in Fig. 2(d). The fully recrystallization annihilated most dislocations in the surface layer, resulting in the significant reduction of FWHM at the surface as shown in Fig. 4. The different expansion coefficients between the recrystallization zone and the deformed sub-surface region induced compressive residual stresses at the surface in both $\sigma_{\|}$and $\sigma_{\perp}$ during the air cooling after $3000 \mathrm{~h}$ thermal exposure. In the sub-surface region, relaxation of the tensile residual stresses was greater in comparison with that after $30 \mathrm{~h}$ thermal exposure due to the longer thermal exposure time. In addition, larger compressive residual stresses were observed as well, as shown in Fig. 3. Studies on the quenching-induced residual stresses in Inconel 718 have indicated that there are no obvious residual stresses induced in the case of air cooling [13]. Therefore, the lager compressive residual stresses in the sub-surface region after 3000 $\mathrm{h}$ thermal exposure are mainly attributed to the initial residual stress state itself in the as-broached specimen and the residual stress relaxation behavior during the thermal exposure. It has been discussed previously that thermal-induced tensile residual stresses and mechanical-induced compressive residual stresses exist simultaneously in machined components. The resultant residual stresses are dependent on whichever effect is stronger. After $3000 \mathrm{~h}$ thermal exposure at $550{ }^{\circ} \mathrm{C}$, the considerable reduction in the tensile residual stresses in the sub-surface layer indicates that the thermal exposure can effectively relax the tensile residual stresses produced by the thermal impact during the broaching. On the other hand, the larger compressive residual stresses reveal that most of the mechanical-induced compressive residual stresses remain after $3000 \mathrm{~h}$ thermal exposure. It shows that the thermal exposure has slight effect on relaxing the compressive residual stresses produced by the mechanical impact during the broaching.

\section{Conclusions}

Residual stresses generated in the broaching operation of Inconel 718 with similar parameters applied in the gas turbine industry have been measured and the influence of thermal exposure at $550{ }^{\circ} \mathrm{C}$ on the residual stresses has been investigated in this study. The major results are summarized as follows:

The broaching operation produces tensile residual stresses at the machined surface. In the subsurface region, a layer with tensile residual stresses forms, followed by a layer several times thicker with compressive residual stresses.

Complete relaxation of the surface tensile residual stresses can be obtained after $30 \mathrm{~h}$ thermal exposure due to the occurrence of recrystallization in the surface layer. However, the short-term thermal exposure has a limited effect on relaxing the residual stresses in the sub-surface region

After $3000 \mathrm{~h}$ thermal exposure, fully recrystallization occurs in the surface layer. Compressive residual stresses forms at the broached surface during the air cooling attributed to the different expansion coefficients between the recrystallization zone and the sub-surface region. The long-term thermal exposure effectively reduces the tensile residual stresses generated due to the thermal impact during the broaching, but has a slight effect on relaxing the compressive residual stresses which instead is associated with the mechanical impact, thereby resulting in larger compressive residual stresses in the sub-surface region. 


\section{Acknowledgement}

Agora Materiae and Strategic Faculty Grant AFM at Linköping University are acknowledged. The scholarship provided by the China Scholarship Council for Mr. Zhe Chen is also appreciated.

\section{References}

[1] I.A. Choudhury, M.A. El-Baradie, Machinability of nickel-base super alloys: a general review, J. Mater. Process. Technol. 77 (1998) 278-284.

[2] D. Dudzinski, A. Devillez, A. Moufki, D. Larrouquere, V. Zerrouki, J. Vigneau, A review of developments towards dry and high speed machining of Inconel 718 alloy, Int. J. Mach. Tools Manuf. 44 (2004) 439-456.

[3] A. Sadat, M. Reddy, Surface integrity of inconel-718 nickel-base superalloy using controlled and natural contact length tools. Part I: Lubricated, Exp. Mech. 32 (1992) 282-288.

[4] A. Sadat, M. Reddy, Surface integrity of inconel-718 nickel-base superalloy using controlled and natural contact length tools. Part II: Unlubricated, Exp. Mech. 33 (1993) 343-348.

[5] A. Sharman, J. Hughes, K. Ridgway, An analysis of the residual stresses generated in Inconel $718^{\mathrm{TM}}$ when turning, J. Mater. Process. Technol. 173 (2006) 359-367.

[6] M. El-Khabeery, M. Fattouh, Residual stress distribution caused by milling, Int. J. Mach. Tools Manuf. 29 (1989) 391-401.

[7] O. Vohringer, Relaxation of residual stresses by annealing or mechanical treatment, Pergamon Press, Adv. Surf. Treat. 4 (1987) 367-396.

[8] I.C. Noyan, J.B. Cohen, Residual stress measurement by diffraction and interpretation, (1987).

[9] A.J. Wilkinson, P.B. Hirsch, Electron diffraction based techniques in scanning electron microscopy of bulk materials, Micron. 28 (1997) 279-308.

[10] V. Bushlya, J.M. Zhou, F. Lenrick, P. Avdovic, J-E. Ståhl, Characterization of White Layer Generated when Turning Aged Inconel 718, Procedia Eng. 19 (2011) 60-66.

[11] M. Moore, W. Evans, Mathematical correction for stress in removed layers in X-ray diffraction residual stress analysis, SAE Technical Paper (1958).

[12] H. Yuan, W. Liu, Effect of the $\delta$ phase on the hot deformation behavior of Inconel 718, Mater. Sci. Eng. A 408 (2005) 281-289.

[13] D. Dye, K. Conlon, R. Reed, Characterization and modeling of quenching-induced residual stresses in the nickel-based superalloy IN718, Metall. Mater. Trans. A 35 (2004) 1703-1713. 